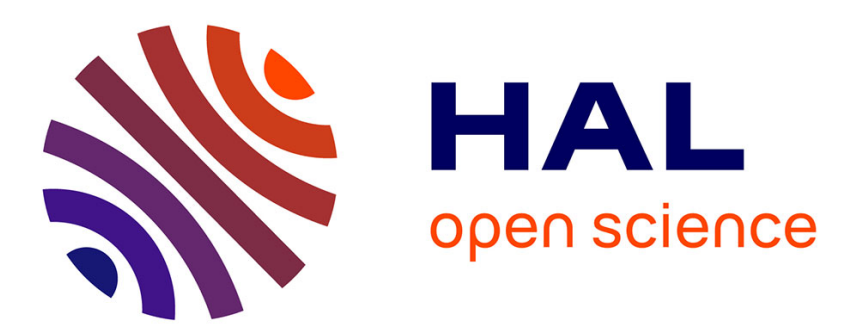

\title{
Design and testing of a magnetic shield for the Thomson scattering photomultiplier tubes in the stray fields of the ERASMUS tokamak
}

\author{
E. Desoppere, G. van Oost
}

\section{- To cite this version:}

E. Desoppere, G. van Oost. Design and testing of a magnetic shield for the Thomson scattering photomultiplier tubes in the stray fields of the ERASMUS tokamak. Revue de Physique Appliquée, 1983, 18 (6), pp.359-361. 10.1051/rphysap:01983001806035900 . jpa-00245103

\section{HAL Id: jpa-00245103 \\ https://hal.science/jpa-00245103}

Submitted on 1 Jan 1983

HAL is a multi-disciplinary open access archive for the deposit and dissemination of scientific research documents, whether they are published or not. The documents may come from teaching and research institutions in France or abroad, or from public or private research centers.
L'archive ouverte pluridisciplinaire HAL, est destinée au dépôt et à la diffusion de documents scientifiques de niveau recherche, publiés ou non, émanant des établissements d'enseignement et de recherche français ou étrangers, des laboratoires publics ou privés. 


\title{
Design and testing of a magnetic shield for the Thomson scattering photomultiplier tubes in the stray fields of the ERASMUS tokamak
}

\author{
E. Desoppere (*) and G. Van Oost \\ Laboratoire de Physique des Plasmas, Association « Euratom-Etat Belge », Ecole Royale Militaire, \\ 1040 Brussels, Belgium
}

(Reçu le 2 novembre 1982, révisé le 4 mars 1983, accepté le 8 mars 1983)

\begin{abstract}
Résumé. - Les phototubes utilisés dans le diagnostic par diffusion Thomson sur le tokamak ERASMUS sont blindés magnétiquement par une série d'écrans coaxiaux. Un champ parasite de $75 \times 10^{-4} \mathrm{~T}$ peut être réduit à $0,01 \times 10^{-4} \mathrm{~T}$ pour un champ parallèle à l'axe du blindage et à $0,03 \times 10^{-4} \mathrm{~T}$ pour un champ perpendiculaire.
\end{abstract}

\begin{abstract}
A multiple coaxial shield system has been designed for the photomultiplier tubes of the ERASMUS tokamak Thomson scattering diagnostic. A stray field of $75 \times 10^{-4} \mathrm{~T}$ was reduced to $0.01 \times 10^{-4} \mathrm{~T}$ for a field parallel to the tube axis, and to $0.03 \times 10^{-4} \mathrm{~T}$ for a perpendicular field.
\end{abstract}

\section{Introduction.}

Shielding of the stray field of big magnets is a frequently encountered problem in nuclear physics experiments and becomes increasingly important in fusion research. The present investigation aims at designing and testing a shield for the PM's of the ERASMUS tokamak Thomson scattering diagnostic which are located in the stray field of the air-core ohmic heating transformer.

\section{Design.}

The shielding factor of an envelope is proportional to the relative magnetic permeability $\mu_{\mathrm{r}}$, multiplied by a geometrical factor. The best enclosure is the smallest seamless hollow sphere, with the highest $\mu_{\mathrm{r}}$. Although magnetic alloys with a $\mu_{\mathrm{r}}$ as high as 300000 are commercially available, the application of a single thick shield in order to avoid saturation is very expensive. A more economical design consists of multiple shields; the thick outer layer is made out of iron to reduce the field, allowing that, going inwards, more expensive thinner layers can be used, with increasing permeability but lower saturation resistance. A practical design for a PM is cylindrical (see Fig. 1). Formulae giving the shielding effect of multiple coaxial cylinders in a homogeneous transverse magnetic field can be found in [1]. For a longi-

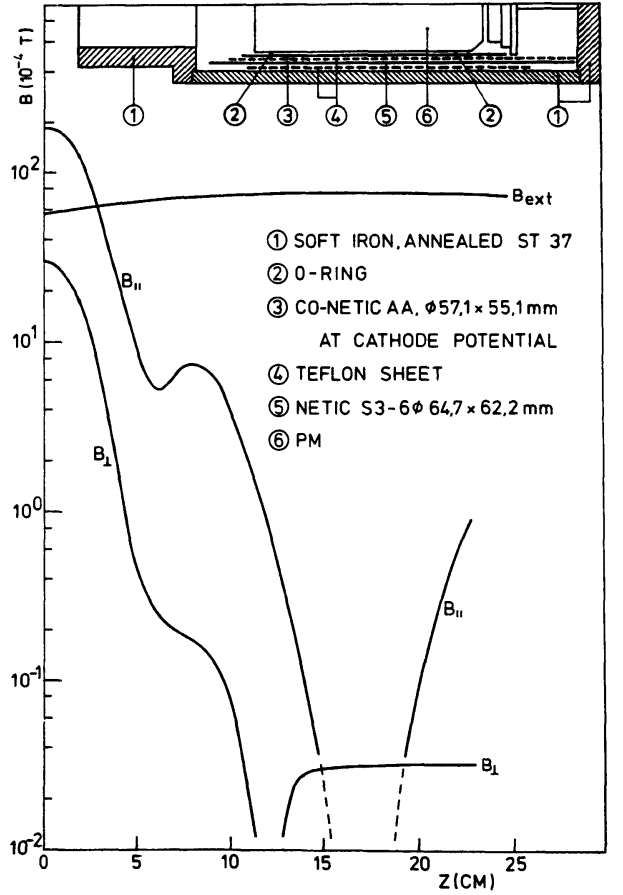

Fig. 1. - Cross-section of PM multilayer magnetic shielding system, and measured spatial variation of $B$ without shield present $\left(B_{\text {ext }}\right)$, and of $B$ parallel $\left(B_{\|}\right)$and $B$ perpendi$\operatorname{cular}\left(B_{\perp}\right)$ to the PM axis.

tudinal field expressions analogous to the formulae in [1] were proposed in [2]. The shielding efficiency in

(*) Laboratorium voor Natuurkunde, Fakulteit Toegepaste Wetenschappen, Rijksuniversiteit, Gent, Belgium 
both longitudinal and transverse fields can be derived analytically [3] for idealized assumptions; the latter reference contains less involved, approximate expressions which can be used for realistic shielding problems without much loss of accuracy.

For a system of $n$ coaxial cylinders, whose axes are perpendicular (1) or parallel (2) to the external field, the approximate expressions are :

$$
\begin{aligned}
& B_{\mathrm{m} 1}=\langle B\rangle .2 R_{1}^{2} /\left(R_{1}^{2}-r_{1}^{2}\right), \\
& B_{\mathrm{m} i}=\frac{B_{\mathrm{m}(i-1}}{\mu_{i-1}} \times \frac{4 r_{i-1}^{2} R_{i}^{2}}{\left(r_{i-1}^{2}-R_{i}^{2}\right)\left(R_{i}^{2}-r_{i}^{2}\right)}, \\
& B_{\mathrm{int}}=B_{\mathrm{m} n} / \mu_{n}, \\
& B_{\mathrm{m} 1}=\langle B\rangle . R_{1}^{2} /\left(R_{1}^{2}-r_{1}^{2}\right), \\
& B_{\mathrm{m} i}=\frac{B_{\mathrm{m}(i-1)}}{\mu_{i-1}} \times \frac{L_{i}^{2}}{4\left(R_{i}^{2}-r_{i}^{2}\right) \ln \left(r_{i-1} / R_{i}\right)}, \\
& B_{\mathrm{int}}=B_{\mathrm{m} n} / \mu_{n}
\end{aligned}
$$

with $B_{\mathrm{m} i}$ : induction inside the material of cylinder $i$; $B_{\text {int }}$ : internal rest field on axis $; \mu_{i}$ : relative permeability; $R_{i}, r_{i}, L_{i}$ : external diameter, internal diameter and length of cylinder $i$; the outer cylinder is infinitely long, all layers are unsaturated. The average induction over the shield $\langle B\rangle$, can be measured or calculated through $\langle B\rangle=B_{\text {ext }} / N$ using the ellipsoid approximation for the demagnetization factor $N$ [4]. Instead of using expressions (1) and (2) or their exact counterparts from reference [3], the occasional designer of a magnetic shield often turns to the following crude formulae giving the shielding efficiency of a single cylinder [5] :

$$
\begin{array}{r}
B_{\mathrm{m}}\left(10^{-4} \mathrm{~T}\right)=(2.5 / 2)(d / t) \times\left(\mu_{0} H_{\mathrm{ext}}\right)\left(10^{-4} \mathrm{~T}\right) \\
\text { for } \mu_{\mathrm{r}} \gg 1 .
\end{array}
$$

$B_{\mathrm{m}}$ : flux density inside the unsaturated material; $d$ : mean diameter along the field lines; $t:$ thickness of the shield; $H_{\text {ext }}$ : external field.

The attenuation $A$ of the field is determined by

$$
A=H_{\mathrm{ext}} / H_{\mathrm{int}}=t \mu_{\mathrm{r}} / d
$$

with $H_{\text {int }}$ the internal rest field.

For a shielding cylinder, the external field penetrates into the open ends and reduces the shielding efficiency; the transition from high external to low internal field is governed by the formula [6]

$$
B_{\text {int }}(z)=B_{\text {ext }} \exp -(k z / R)
$$

with $k=2.42$ if the shield is parallel, 3.83 if the shield is perpendicular to the cylinder axis; $R$ is the inner radius of the cylinder.

A triple layer magnetic shield (Fig. 1) was designed relying on expressions (1) and (2). The outer dimensions of the housings were imposed by already exist- ing mechanical supports and by the fact that the outer envelope should support existing diaphrams.

\section{Testing.}

Tests were performed in the field of a $46 \mathrm{~cm}$ diameter Helmholtz configuration. The cylinders were equipped with coils to measure the average flux $\langle B\rangle$ over the complete shield; the variation of field strength inside the shields was determined on axis as a function of distance $z$, using either a Rawson (rotating coil type) Gaussmeter or a Hall effect device (Empire Scientific Co. model 900). $B_{\text {ext }}(z)$ and $B_{\text {int }}(z)$ are shown in figure 1 . The measured values of the internal rest field are compared :

a) with values obtained by applying expressions (3) and (4); for each layer the rest field of an outer layer is taken as a uniform, infinitely extended external field acting on the next inner layer;

b) with more exact formulae (1) to (2).

The transition from external to internal field, and from higher to lower field regions inside the shield, was assumed to take place according to the exponential law (5).

All data are summarized in table I. From figure 1 and table $I$ the following conclusions can be drawn :

- For $B$ perpendicular to the tube axis measured values and values calculated in the ellipsoid approximation agree well. For a parallel field there is less good agreement; this is mainly due to the joint between cap and main body. The reluctance of an air gap in series with two ferromagnetic objects is liable to affect the magnetic properties of the whole system more then in the case where the gap is parallel to the field lines, and field leakage will be larger.

- The approximate formulae provide satisfactory results if a single layer is considered. However, these formulae, applied to multiple shields overestimate the shielding efficiency. The assumption that the inner field can be taken as a uniform, infinitely extended external field for the next layer is clearly invalid for the spacings between successive layers encountered here.

- The penetration of a stronger field into a region of weaker field strength behaves following (5); it also explains qualitatively the discontinuity in the decay of the fields as they penetrate into the region of minimum field.

\section{Conclusion.}

A triple layer shielding system has been designed and built relying on analytical magnetostatic formulae. Tests on a full size model were performed to verify the shielding efficiency. Good agreement is found with predictions from relatively exact expressions while approximate formulae severely overestimate the shielding efficiency of multiple shields, these formulae only being valid for single layer cylinders. 
Table I.

$B_{\text {ext }}=76 \times 10^{-4} \mathrm{~T}$.

\begin{tabular}{|c|c|c|c|c|c|c|}
\hline & \multicolumn{3}{|c|}{$B \perp$ to $\mathrm{PM}$ axis } & \multicolumn{3}{|c|}{$B / /$ to $P M$ axis } \\
\hline & measured & calcul. (1) & calcul. (3) & measured & calcul. (2) & calcul. (3) \\
\hline$\langle B\rangle$ & 175 & $166(N=0.46)$ & & 1390 & $878(N=0.087)$ & \\
\hline $\begin{array}{c}\text { single layer ST } 37 \\
B_{\mathrm{m} 1} \\
B_{\mathrm{int} 1}\end{array}$ & 0.48 & $\begin{array}{l}881 \\
0.64\end{array}$ & $\begin{array}{l}808 \\
0.48\end{array}$ & 1.20 & $\begin{array}{l}3500 \\
1.32\end{array}$ & $\begin{array}{c}2328 \\
0.80\end{array}$ \\
\hline $\begin{array}{l}\text { double layer ST } 37 \\
+ \text { Netic } \\
B_{\mathrm{m} 2} \\
B_{\text {int2 }}\end{array}$ & 0.36 & $\begin{array}{l}444 \\
0.30\end{array}$ & $\begin{array}{l}30.5 \\
0.16\end{array}$ & 1.14 & $\begin{array}{l}2088 \\
0.529\end{array}$ & $\begin{array}{l}175 \\
0.21\end{array}$ \\
\hline $\begin{array}{c}\text { triple layer ST } 37 \\
+ \text { Netic }+ \text { Co-Netic } \\
B_{\mathrm{m} 3} \\
B_{\text {int3 }} \\
B \text { in } 10^{-4} \mathrm{~T}\end{array}$ & $\lesssim 3 \times 10^{-2}$ & $1.2 \times 10^{-3}$ & $\begin{array}{c}11.5 \\
4 \times 10^{-4}\end{array}$ & $<1 \times 10^{-2}$ & $\begin{array}{c}1007 \\
3.47 \times 10^{-3}\end{array}$ & $\begin{array}{c}42.5 \\
1.4 \times 10^{-3}\end{array}$ \\
\hline
\end{tabular}

\section{References}

[1] WAdey, W. G., Rev. Sci. Instrum. 27 (1956) 910.

[2] Gubser, D. U., Wolf, S. A. and Cox, J. E., Rev. Sci. Instrum. 50 (1979) 751.

[3] TAVernier, S., VAN Den Bogaert, F., VAN LANCKer, L., Nucl. Instrum. Methods 167 (1979) 391.
[4] Osborne, J. A., Phys. Rev. 67 (1945) 351.

[5] Kaden, H., BergmanN, J. F., Ed., Wirbelströme und Schirmung in der Nachrichtentechnik (2 Aufl. Berlin Springer, München) 1959.

[6] MAYER, A., Z. Angew. Phys. 23 (1967) 381. 